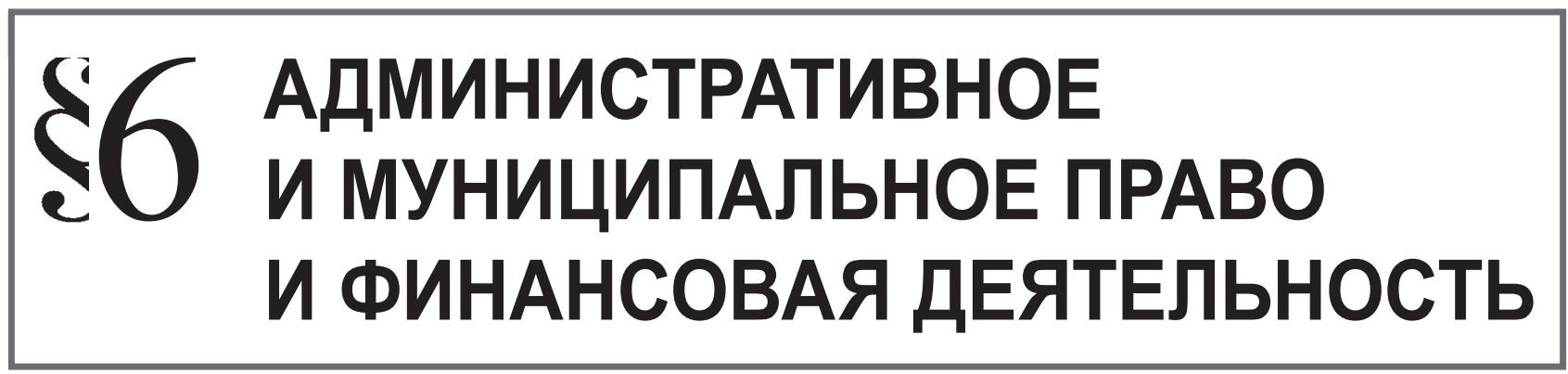

DOI: $10.7256 / 1999-2807.2013 .06 .8$

Ю.И. Фрейдина

\title{
ЭМИССИОННОЕ ПРАВО В РОССИИ: ПОЛИТИКО-ПРАВОВЫЕ ПРЕДПОСЫЛКИ СТАНОВЛЕНИЯ И РАЗВИТИЯ
}

$\mathrm{H}$ е вызывает сомнения, что для любого государства важнейшей задачей в разные периоды его развития являлось осуществление «грамотной» денежно-финансовой политики, связанной с регулированием доходной и расходной частей государственного бюджета (казны).

«Исследование природы тех или иных видов государственных доходов (налогов, доменов, регалий), а также их правовое закрепление позволяет анализировать не только финансово-бюджетную деятельность, но и стиль государственной политики в целом ${ }^{1}$.

Кроме того, изучение институтов фискальных монополий, государственных регалий и других финансовых прерогатив государства и их эволюции «дает возможность оценить государство и как субъекта публично-властных отношений, и как предпринимателя и активного участника торговых отношений внутри страны и за ее пределами»².

Если вести речь о наиболее традиционной точке зрения относительно сущности и правовой природы общественных отношений, составляющих предмет эмиссионного права как подотрасли финансового права в современном его понимании, отметим, что историко-правовые аспекты возникновения денег и

1 Брызгалин А.В., Щербакова Е.С., Федорова О.С., Харалгина О.Л., Вятчинова Т.И., Королева М.В., Головкин А.Н., Аникеева О.Е., Безбородова Т.М., Козина Е.В., Сунцева П.В., Ларина О.Г., Бабенко М.Г., Пелымская И.С., Бачурин Д.Г., Волкова-Гончарова Т.А., Новикова В.Е., Есенжулова Л.С., Медведев С.О., Жернаков С.А., Еремина М.В., Загвоздина В.Н., Зозуля В.В., Ляпина Т.М., Сякин Р.Р., Тюпакова Н.Н., Феоктистова Т.В., Шадурская М.М., Новоселов К.В., Ядренникова Е.В. Кредиты и займы: бухгалтерский и налоговый учет // Налоги и финансовое право. - 2010. - № 6. - С. 17.

2 Брызгалин А.В., Щербакова Е.С., Федорова О.С. и др. Указ. соч. - С. 21. денежных повинностей, появления денежного обращения, а также перехода от неденежных повинностей к денежным достаточно подробно рассмотрены в научных исследованиях И.И. Кучерова ${ }^{3}$, Н.М. Артемова, Л.Л. Арзуманова, А.А. Ситник ${ }^{4}$ В.В. Святловского $^{5}$, С.Я. Боженка ${ }^{6}$, И.И. Кауфмана ${ }^{7}$, Н.А. Размановой ${ }^{8}$ и целого ряда других ученых. Согласно позиции названных авторов, в первую очередь, И.И. Кучерова и В.В. Святловского, в качестве главной предпосылки возникновения денег следует рассматривать зарождение меновых отношений. В свою очередь, последние возникают одновременно с появлением личной свободы и движимого имущества. Самые первые такие отношения следует числить с момента миролюбивых сношений двух кланов, родов или племен между собою. Обмен внутри семьи, клана, рода не мог существовать в принципе, поскольку для него необходимо наличие товара со стороны. Вместо обмена широко были распространены отношения дарения, раздела добычи, наследования и пр. При этом дарение посте-

\footnotetext{
Кучеров И.И. Историко-правовые аспекты возникновения денег и денежных повинностей // История государства и права. - 2011. - № 17. - С. 20-26.

4 Денежное право (Финансово-правовое регулирование обращения национальной и иностранной валюты на территории РФ): коллективная монография. - М.: Элит, 2011. - 272 с.

5 Происхождение денег и денежных знаков. 2-е изд. - М., 2010.

6 Генезис доходов государства: монография. - М., 2010. C. 12 .

7 Русский вес, его развитие и происхождение в связи с историей русских денежных систем с древнейшего времени. 2-е изд. М., 2011. С. $69-80$.

8 Финансовая политика Российской империи (XVIII - первая половина ХІХ вв.): курс лекций. - М., 2008. - С. 176-196.
} 
пенно стало сопровождаться отдариванием, и это уже в известной степени напоминало обмен. Однако отчетливое и полное развитие обмена наступает много позднее, с появлением товарных рынков. Именно на этой стадии развития обмена возникает потребность в универсальном средстве обращения, которым первоначально служили отдельные товары ${ }^{9}$.

В настоящее время, говоря о функциях современного государства в меняющемся мире, учитывая развитие как международного сотрудничества, так и межгосударственных противоречий, уровень современных вызовов и угроз интересам личности, общества и национальной безопасности отдельно взятой страны, появляются и новые подходы к исследованию как сущности государства, так и его функций в экономической, социальной, политической и духовной сферах общественной жизни. В мировом сообществе речь идет как минимум о двух принципиальных вещах: «о сохранении государственного суверенитета (проблема, вставшая особенно отчетливо на фоне американских вторжений в различные страны) и о возрастании конкуренции между государствами, включая степень эффективности систем государственного администрирования как одного из ключевых факторов обеспечения национальной конкурентоспособности в современном мире» ${ }^{10}$. Безусловно, сказанное имеет непосредственное отношение и к экономической сфере общественной жизни. При этом «эффективное развитие экономики страны во многом определяется состоянием денежного обращения, стабильным функционированием денежной системы» ${ }^{11}$.

Учитывая изложенное, а также тот факт, что в рамках традиционного подхода финансово-правовой науки под эмиссионном правом понимается совокупность правовых норм, регулирующих порядок выпуска, обращения и изъятия из обращения законных средств платежа в наличной форме (наличных денег) ${ }^{12}$, прежде чем вести речь об исторических этапах становления организационно-правовых форм осуществления эмиссионной деятельности на территории нашего го-

9 См.: Святловский В.В. Происхождение денег и денежных знаков. 2-е изд. - М., 2010. - С. 12., Кучеров И.И. Историко-правовые аспекты возникновения денег и денежных повинностей // История государства и права. - 2011. - № 17. - С. 21.

10 Хабибулин А.Г., Селиванов А.И. Стратегическая безопасность российского государства: политико-правовое исследование. - М., 2008. - С. 6.

11 Горбунова О.Н., Грачева Е.Ю. Финансовое право: учебник / отв. ред. Е.Ю. Грачева, Г.П. Толстопятенко. - М.: «Проспект», 2004. - С. 356.

12 Лисицын А.Ю. Систематизация в эмиссионном праве // Реформы и право. - 2012. - № 4. - С. 8. сударства, отметим, что в настоящее время существует целый ряд исследований, которые расширяют названный подход и включают в предмет эмиссионного права, например, вопросы безналичного денежного обращения, формы безналичных расчетов, в том числе посредством электронных платежных документов, а также правила ведения кассовых операций кредитными организациями ${ }^{13}$.

Более того, в предмет эмиссионного права в широком смысле включаются вопросы валютного регулирования и валютного контроля ${ }^{14}$, а также вопросы противодействия легализации доходов, полученных преступным путем, и финансированию терроризма ${ }^{15}$. При этом отмечается, что «в теории пока должным образом не оценена цементирующая роль институтов эмиссионного права в системе финансового права. Представляется, что эмиссия и регулирование движения денежной массы в конечном счете играют роль центральной несущей конструкции для всего финансового механизма и, следовательно, являются основным элементом системы финансового права ${ }^{16}$.

Таким образом, рассмотрим исторические этапы становления организационно-правовых форм осуществления эмиссионной деятельности на территории нашего государства не только с точки зрения соответствующих социально-экономических и политико-правовых предпосылок, но и во взаимосвязи с вопросами обеспечения экономико-финансовой безопасности, в том числе с вопросами правового регулирования государственных доходов и расходов.

Обратим внимание, что аналогичного рода рассуждения о социально-экономических предпосылках становления организационно-правовых форм осуществления эмиссионной деятельности можно встретить еще в трудах К. Маркса, Ф. Энгельса.

Известно, что лишь на высшей ступени варварства начался быстрый рост населения, сопровождающийся появлением отдельных густонаселенных местностей. В это время уже возникло полеводство и товарное производство, прочно вошли в обиход усовершенствованные железные орудия, кузнечный мех, ручная

13 Бельский К.С. Эмиссионное право как институт финансового права // Государство и право. - 2006. - № 5. - С. 53.

14 Запольский С.В. Глобализация экономики: финансовоправовой аспект // Финансовое право. - 2011. - № 11. - С. 2-6.

15 Финансовое право: учебник / А.Р. Батяева, К.С. Бельский, Т.А. Вершило и др.; отв. ред. С.В. Запольский. - М., 2011. - C. 43.

16 Лисицын А.Ю. Систематизация в эмиссионном праве // Реформы и право. - 2012. - № 4. - С. 10. Финансовое право: учебник / А.Р. Батяева, К.С. Бельский, Т.А. Вершило и др.; отв. ред. С.В. Запольский. - М., 2011. - С. 43 
мельница, гончарный круг, изготовление растительного масла и виноделие, развитая обработка металлов, переходящая в художественное ремесло, изготавливаются повозки и боевые колесницы, распространена постройка судов, обнаруживаются зачатки архитектуры и строятся города. Последние стали служить постоянным местопребыванием знати, которая обогащалась благодаря ростовщичеству и торговле, сосредотачивая в своих руках денежные богатства. Родовому же строю деньги не были ведомы, поскольку члены рода сами потребляли все то, что добывали и производили. Иными словами, при родовом строе продукты целиком находились во власти производителей, что исключало превращение их в товары ${ }^{17}$.

По выражению С.П. Покровского, «Возникновение денег возможно только на известной степени развития народа. Пока разделение труда...еще недостаточно широко, пока...не существует правильного предложения товаров, и каждый по возможности произведениями собственного труда удовлетворяет первые потребности жизни, до тех пор простой мены достаточно для оборота.... Более широкое разделение труда, развитие производства и потребления в народе обусловливают переход к денежному хозяйству ${ }^{18}$.

Соответственно, зарождение денежного обращения следует связывать именно с моментом перехода от натурального хозяйства к товарному производству. Существовавший ранее обмен товарами постепенно стал сдерживать развитие торговли, что и создало предпосылки для возникновения денежного обращения.

Как отмечено выше, отправным моментом интересующих нас процессов является возникновение примитивного обмена товарами с использованием так называемых товарных денег, в качестве которых служили наиболее востребованные товары: скот, зерно, масло, а также оружие, ткани, посуда, украшения и иная утварь. Это, впрочем, не исключало использования в качестве товарных денег и иных предметов, в частности сугубо природного происхождения, таких как шкуры и зубы диких животных, птичьи перья, раковины, жемчуг и пр. ${ }^{19}$

17 См.: Энгельс Ф. Происхождение семьи, частной собственности и государства: в связи с исследованиями Льюиса Г. Моргана. 3-е изд. - М., 2010. - С. 27, 122.

18 См.: Покровский С.П. О деньгах // Московские университетские известия. - 1869. - № 8. - С. 551, Кучеров И.И. Историко-правовые аспекты возникновения денег и денежных повинностей // История государства и права. - 2011. № $17 .-$ C. 24.

19 Кучеров И.И. Историко-правовые аспекты возникновения денег и денежных повинностей // История государства и права. - 2011. - № 17. - С. 22.
Таким образом, на самом раннем этапе отбывание повинностей сводилось преимущественно к труду или отчуждению продуктов питания и иного имущества (но не денег), принадлежащих частным лицам в пользу публичной власти.

В этой связи, учитывая явно выраженный натуральный характер взиманий, существовавших на ранних этапах зарождения государственности, наиболее актуальным для целей настоящего параграфа диссертационного исследования представляется вопрос относительно того, с какого момента возникают денежные повинности, а деньги становятся средством их уплаты.

Развитие товарных денег сначала идет по пути утверждения того или иного наиболее популярного в той или иной местности или у того или иного народа продукта, как всеми признаваемого средства обращения, обладающего определенной мерой стоимости. Известно, например, что в качестве меры стоимости в Древнем Риме и Эфиопии использовалась каменная соль, а в Скандинавии - сушеная рыба. Такие товары использовались в качестве основной счетной единицы, на которой основывался товарный тариф, закрепляющий определенное установившееся соотношение этой единицы с другими товарами. Однако тот или иной товар, являющийся излюбленным у одних народов, мог совершенно не пользоваться спросом у других ${ }^{20}$.

20 В конечном счете естественным путем круг товарных денег стал сужаться, прежде всего посредством исключения из него товаров, имеющих сугубо локальный спрос. Это привело к упрочению позиций тех товаров, которые стали служить средством обращения во внешней торговле, поскольку такие товары получили наиболее широкое признание и устойчивый спрос вовне. К примеру, у славян изначально таковыми товарами служили шкурки пушных животных - белок, куниц, лисиц и др. При этом наряду с обращением целых шкурок имело также место использование отдельных их частейсвоеобразных расчетных символов, включая беличьи уши или куньи головы - «морды». Однако именно меха со временем стали служить главным товаром во внешней торговле с другими государствами, поскольку они пользовались высоким спросом. Не случайно дань, которая являла собой одну из первых форм обложения на Руси, также собиралась преимущественно мехами. Наряду с этим дань уплачивалась различными сырыми продуктами, которые также пользовались устойчивым спросом, включая скот, зерно, мед, лен и пр. Подробнее см.: Святловский В.В. Указ. соч. - С. 13-14; См.: Гурьев А. Денежное обращение в России в XIX столетии: Исторический очерк. - СПб., 1903. С. 1-2; См.: Козлов С.А., Дмитриева 3.В. Налоги в России до XIX в.: курс лекций. 2-е изд., испр. и доп. - СПб., 2001. - С. 7; История финансового законодательства России: учеб. пособие / отв. ред. И.В.Рукавишникова.-М.-Ростовн/Д,2003.-С.18,КучеровИ.И. Историко-правовые аспекты возникновения денег и денежных повинностей // История государства и права. - 2011. № 17. - С. 20-26. 
Тем не менее, в определенный момент в составе товарных денег стали выделяться металлы. Последние также исстари стали использоваться в качестве универсального средства обмена, при этом изначально они обращались в виде различного рода слитков и кусков, не имеющих каких-либо публичных клейм. В зависимости от местности виды обращающихся металлов могли различаться ${ }^{21}$.

Вместе с тем, в этот период металлы еще не являются единственным средством обращения, поэтому используются в обороте наряду с иными товарными деньгами. Однако постепенно, по образному выражению В.В. Святловского: «Среди последних вышел победителем прочный, стойкий и красивый товар - металлы, а из них вскоре одни металлы благородные»22 .

Именно с появлением металлов, по мнению диссертанта, следует связывать новый этап в становлении как денежного обращения, так и организационно-правовых форм осуществления эмиссионной деятельности, в том числе, на территории нашего государства, поскольку торговцы начинают металлы взвешивать, и вес, как более точное основание измерения, постепенно вытесняет в торговле обычный счет предметов.

«Точность в торговых расчетах вызвала необходимость в официальном удостоверении веса и чистоты обращающегося металла, что, в свою очередь, породило практику клеймения слитков» ${ }^{23}$.

В свою очередь, взвешивание металла на основе тех или иных мер веса привело к возникновению денежных систем, включающих в себя определенное количество денежных единиц определенного же вида и веса ${ }^{24}$. В период, когда в обращении находились пре-

21 Так, в Древней Спарте таковым металлом являлось желе30, а в Древнем Риме и в Древнем Китае - медь. Именно эти металлы, а также свинец и олово, и металлические сплавы, например бронза, из которых, как правило, изготавливались предметы военного и бытового предназначения, изначально и стали служить делу становления денежного обращения. Со временем в оборот также были вовлечены серебро и золото. Первоначально металлы все еще больше являлись товаром, а не деньгами в современном их представлении, поскольку имели самый различный вид, начиная от бесформенных кусков металла, различных металлических слитков или проволоки вплоть до вида, напоминающего фигурки животных, а также предметы военного снаряжения и утвари - наконечники стрел, лопаты, мотыги, ножи, рыболовные крючки и т.п.

22 См.: Святловский В.В. Указ. соч. - С. 15-16.

23 Кучеров И.И. Историко-правовые аспекты возникновения денег и денежных повинностей // История государства и права. - 2011. - № 17. - С. 24.

24 Истории нумизматики хорошо известна такая мера веса, как древнеримская либра, которая соответствовала 327,45 грамма и из которой чеканилось 72 золотых ауреуса. Аналогичные параметры имела и византийская литра. Опреде- имущественно золотые и серебряные монеты, покупательная способность денег определялась на основе стоимости соответствующего благородного металла. Это обстоятельство исключало какие-либо проблемы обмена денежных знаков одного государства на денежные знаки другого государства, поскольку за основу в этом случае принимался вес монеты и рыночная стоимость соответствующего металла.

Действительно, основным материалом для изготовления монет постепенно стали служить серебро и золото, поскольку в наилучшей степени подходили для использования в качестве всеобщего эквивалента. Это объяснялось тем, что именно эти благородные металлы обладали такими признаками, как широкая востребованность, высокая стоимость, качественная однородность, объединяемость, делимость и сохраняемость. Покупательная способность денег определялась степенью популярности среди населения той или иной монеты и готовностью принимать ее в оплату, которые, в свою очередь, непосредственно зависели от веса и пробы содержащегося в ней драгоценного металла. В этой связи уместно привести суждение Адама Смита, который заметил, что «в каждый момент и в каждом данном месте деньги какой-либо страны представляют собой более или менее точное мерило стоимости в соответствии с тем, насколько находящаяся в обращении монета более или менее точно соответствует своему узаконенному масштабу или содержит более или менее точно то самое количество чистого золота или чистого серебра, которое она должна содержать» ${ }^{25}$.

С момента появления денег берет свое начало история денежных же повинностей. Однако еще довольно продолжительное время в силу объективных причин, в том числе из-за неразвитости денежного обращения, эти повинности взимаются наряду с неденежными. Более того, в истории существуют примеры, когда проблемы денежного обращения приводили к возобновлению или расширению натурального обложения ${ }^{26}$.

ленный вес имела и древнерусская гривна. - См. подробнее: Кауфман И.И. Русский вес, его развитие и происхождение в связи с историей русских денежных систем с древнейшего времени. 2-е изд. - М., 2011. - С. 69-80, Кучеров И.И. Историко-правовые аспекты возникновения денег и денежных повинностей // История государства и права. -2011 . - № 17. C. 20-26.

25 См.: Смит А. Исследование о природе и причинах богатства народов. Серия «Антология экономической мысли»/ Пер. с англ. - М., 2007. - С. 102.

26 К примеру, в Византии при Диоклетиане (284-305 гг.) введен поземельный налог - аннона, взимавшийся в натураль- 
Самые первые сведения о чеканке монет на Руси относятся к X в.; соответствующим правом, в частности, первыми воспользовались правители Московского и Киевского княжеств. Так, киевский князь Владимир Мономах осуществил чеканку ставших впоследствии известными монет из серебра («сребреники») и из золота («златники»). Впоследствии монеты стали чеканиться и другими князьями, соответственно, в денежное обращение поступало большое количество существенно различающихся по наименованию, виду, размеру и весу денежных знаков ${ }^{27}$.

Использование же при именовании русской денежной единицы широко известных слов "рубль», а применительно к его доле - «копейка» укоренилось значительно позже. Впервые употребление слова «рубль» при письме обнаруживается в новгородской берестяной грамоте, датированной 1281-1299 гг. Изначально рублями (от слова «рубить») стали именовать отрубленные от служившей украшением шейной гривны части - куски в четверть серебряного прута, имевшего длину до 20 сантиметров и вес около 200 граммов. Начиная с XV в., когда стала чеканиться новая русская монета - «деньга», ставшая на некоторое время основной денежной единицей, рубль фактически стал выполнять лишь функцию счетной единицы и состоял из стопы в 200 таких монет. В конечном счете в обращение стали поступать так называемые московские деньги - «московки» и новгородские деньги «новгородки». На аверсе последних присутствовало изображение всадника с копьем (отсюда - «копейка»). Поскольку новгородская монета приравнивалась к двум московским монетам, счетный рубль стал составлять сто копеек. Фактически тем самым обозначился процесс формирования централизованной денежной системы, которая в конечном счете и положила конец феодальной чеканке ${ }^{28}$.

Тем не менее, чеканка монет долгое время не являлась исключительной прерогативой князей, поэтому их изготовление осуществлялось также частными

ной форме. Взимание налога именно в такой форме было обусловлено финансовым кризисом, практически дезорганизовавшим монетарную систему государства. Натуральный же налог в этот период в наилучшей степени обеспечивал стабильное снабжение продовольствием армии, чиновничества и жителей городов и в первую очередь столицы. - См.: Панов Е.Г. Социальная реальность теократических налоговых систем: монография. - М., 2009. - С. 110-111.

27 См. подробнее: Чертков А. Описание древних русских монет. - М., 1834, Кучеров И.И. Историко-правовые аспекты возникновения денег и денежных повинностей // История государства и права. - 2011. - № 17. - С. 23.

28 См.: Прохорова Н.В. Монеты и банкноты России. - М., 2009. - C. 64 лицами - «денежниками». Многочисленные злоупотребления со стороны последних, заключающиеся в выпуске монеты более легкой по весу и менее чистой по содержанию металла, часто служили поводами для народных волнений ${ }^{29}$. Все это указывает на то, что в указанный период еще не утвердилось монопольное право публичной власти на денежную эмиссию. Соответственно на тот период времени отсутствовало единство денежной системы, что, в свою очередь, не способствовало окончательному утверждению денег в качестве средства уплаты податей.

Кроме того, следует принять во внимание тот факт, что в свободном обращении наряду с русскими монетами также находились изготовленные из драгоценных металлов монеты других государств, при этом их использование в хозяйственном обороте в качестве средства платежа в малой степени зависело от чьейлибо воли. Как метко заметил Давид Риккардо, «драгоценные металлы, употребляемые для обращения товаров всего мира, распределялись ... в известных пропорциях между различными цивилизованными нациями земного шара соответственно состоянию их торговли и богатства, а следовательно, и соответственно числу и частоте платежей, которые им приходилось производить. При таком распределении драгоценные металлы всюду сохраняли одну и ту же стоимость» ${ }^{30}$. Основным источником поступления иностранных денег на Руси в это время являлась внешняя торговля с Византией, государствами Центральной Европы и Средней Азии. В частности, в денежном обращении широко использовались византийские монеты - милиаренсы, пенсы германских и англосаксонских княжеств, куфические дирхамы арабских султанатов ${ }^{31}$. В описаниях того времени обнаруживается интересный факт, что, испытывая нехватку серебра и золота, русские князья, стремясь сохранить в обращении на своей территории иностранные монеты из драгоценных металлов, обязывали своих подданных переходить в торговле на обмен товарами, например используя для этого меха, недостатка в которых не было ${ }^{32}$.

29 См.: Гурьев А. Денежное обращение в России в XIX столетии: Исторический очерк. - СПб., 1903. - С. 1-2.

30 См.: Рикардо Д. Начала политической экономии и налогового обложения. Избранное / Пер. с англ. - М., 2007. Серия «Антология экономической мысли». - С. 720.

31 См.: Попырин В.И. Очерки истории денег в России. - М., 1948. - С. 12-13; Кучеров И.И. Историко-правовые аспекты возникновения денег и денежных повинностей // История государства и права. - 2011. - № 17. - С. 25.

32 См.: Герберштейн С. О монете // Московия / Пер. А.И. Малеина и А.В. Назаренко. Комментарий 3. Ножниковой. - Москва - Владимир, 2008. - С. 192. 
Не случайно одно из первых упоминаний об использовании на Руси денег при уплате дани приходится на тот период, когда процесс становления отечественной денежной системы находился еще на самой начальной стадии. Так, в летописи упоминается, что в IX в. радимичи и вятичи платили дань сначала хазарам, а потом киевскому князю «по шлягу от рала». В свое время известный русский историк В.О. Ключевский полагал, что шлягом являлась арабская монета, широко использовавшаяся в то время в торговом обороте ${ }^{33}$.

Тем не менее, в силу ограниченности собственного денежного обращения на протяжении нескольких последующих столетий на Руси преобладали неденежные повинности, имеющие различные способы отбывания. Как отмечает В.И. Сергеевич, «наши древние волости-княжения с первого своего появления на свет божий возлагали на своих подданных разные повинности. Древнейшее известие о них относится к княжению св. Ольги; говорит о повинностях и «Русская Правда» и даже в своей древнейшей редакции. По новгородским памятникам XIII в. все население этого обширного княжения, городское и сельское, несет повинности в пользу государства и расписано для этой цели в разные «потуги». Московские памятники говорят «о тягле». Потуг и тягло - слова одного корня; ими обозначается обязанность населения нести государственные повинности» ${ }^{34}$.

33 Цит. по: Петухова Н.Е. История налогообложения в России IX-XX вв.: учеб. пособие. - М., 2008. - С. 11; Кучеров И.И. Историко-правовые аспекты возникновения денег и денежных повинностей // История государства и права. - 2011. № $17 .-$ C. 23.

34 Анализ древнейших форм обложения на Руси свидетельствует о том, что, к примеру, повинность, именуемая «корм», буквально представляла собой обязанность по поставке пищевого довольствия чиновнику (вирнику). Повинности, называемые «городовое дело» и «мостовщина», изначально предполагали участие городского и сельского населения соответственно в постройке укреплений вокруг городов и в устройстве мостов через реки, строительстве дорог и деревянных настилов на улицах. «Княжое дело» обязывало участвовать в постройке и обустройстве княжеского двора, вспахивать и окашивать княжеские земли, обмолачивать хлеб, запасать дрова, участвовать в охотничьих загонах и т.п. - См.: Сергеевич В.И. Тягло и порядок обложения // Древности русского права: в 3 т. / Под ред. и с предисл. А. Томсинова. - М., 2006. Т. 3: Землевладение. Тягло. Порядок обложения. - С. 127.
Учитывая цели, заявленные при рассмотрении вопросов данного раздела настоящего диссертационного исследования, обратим внимание, что с точки зрения трансформации неденежных повинностей в денежные наибольший интерес представляют повинности, связанные с поддержанием обороноспособности и обеспечения безопасности государства ${ }^{35}$.

Утверждение денег в качестве средства уплаты повинностей происходило постепенно, по мере формирования единой национальной денежной системы и развития денежного обращения. Археологические же исследования монетных кладов того времени из-за преобладания в них золотоордынских и иных иностранных монет, свидетельствуют о том, что на рубеже XIV-XV вв. на собственно русских землях внутренняя торговля и денежное обращение все еще находились в зачаточном состоянии ${ }^{36}$. Лишь в результате денежной реформы 1535-1538 гг. в России введена государственная монополия на чеканку монеты. Однако фактически лишь спустя еще сто лет в стране окончательно установилась единая денежная система с единственным эмиссионным центром Московским монетным двором. Перевод уплаты всех государственных имущественных повинностей на деньги окончательно был осуществлен лишь в середине XVI в. ${ }^{37}$

\footnotetext{
35 Изначально ратная служба, как исключительно натуральная повинность, предполагала обязанность по выставлению определенного числа ратных людей, конных и пеших, во всеоружии, с необходимым запасом продовольствия и фуража на весь период военных действий. Постепенно наряду с этим стал практиковаться сбор на эти же цели денег, за счет которых осуществлялся наем ратных людей на государеву военную службу. Такие повинности, как «засечное дело» и «ямчужное дело», предусматривали обязанности соответственно в создании различных препятствий на пути наступающего противника и доставлении селитры для приготовления пороха. Последняя повинность со временем трансформировалась в обязанность уплачивать «пищальные деньги», за счет которых приобреталось огнестрельное оружие. Позднее состав рассматриваемых денежных повинностей дополнили так называемые полоняничные деньги - налог, средства от уплаты которого использовались для выкупа пленных - См. подробнее: Сергеевич В.И. Указ. соч. - С. 156-161, Кучеров И.И. Историко-правовые аспекты возникновения денег и денежных повинностей // История государства и права. - 2011. - № 17. - С. 25.

36 См.: Мельникова А.С., Дядченко О.С. Монетные клады (сводка кладов и сведений о находках). - М., 1994. - С. 5; Кучеров И.И. Историко-правовые аспекты возникновения денег и денежных повинностей // История государства и права. - 2011. - № 17. - C. 25.

37 См.: Козлов С.А., Дмитриева 3.В. Указ. соч. - С. 34.
} 


\section{Библиографический список:}

1. Бельский К.С. Эмиссионное право как институт финансового права // Государство и право. - 2006. - № 5. - С. 53.

2. Генезис доходов государства: монография. - М., 2010. - С. 12.

3. Герберштейн С. О монете // Московия / Пер. А.И. Малеина и А.В. Назаренко. Комментарий 3. Ножниковой. Москва - Владимир, 2008. - С. 192.

4. Горбунова О.Н., Грачева Е.Ю. Финансовое право: учебник / отв. Ред. Е.Ю. Грачева Г.П. Толстопятенко. М.: «Проспект», 2004. С. 356.

5. Гурьев А. Денежное обращение в России в XIX столетии: Исторический очерк. - СПб., 1903. - С. 1-2.

6. Денежное право (Финансово-правовое регулирование обращения национальной и иностранной валюты на территории РФ): Коллективная монография. - М.: Элит, 2011. - 272 с.

7. Запольский С.В. Глобализация экономики: финансово-правовой аспект // Финансовое право. - 2011. № 11. - С. 2-6.

8. Кучеров И.И. Историко-правовые аспекты возникновения денег и денежных повинностей // История государства и права. - 2011. - № 17. - С. 20-26.

9. Лисицын А.Ю. Систематизация в эмиссионном праве // Реформы и право. - 2012. - № 4. - С. 10.

10. Мельникова А.С., Дядченко О.С. Монетные клады (сводка кладов и сведений о находках). - М., 1994. - С. 5.

11. Петухова Н.Е. История налогообложения в России IX-XX вв.: учеб. пособие. - М., 2008. - С. 11.

12. Покровский С.П. О деньгах // Московские университетские известия. - 1869. - № 8. - С. 551, Кучеров И.И. Историко-правовые аспекты возникновения денег и денежных повинностей // История государства и права. 2011. - № 17. - С. 24.

13. Попырин В.И. Очерки истории денег в России. - М., 1948. - С. 12-13. Кучеров И.И. Историко-правовые аспекты возникновения денег и денежных повинностей // История государства и права. — 2011. - № 17. - С. 25.

14. Происхождение денег и денежных знаков. 2-е изд. - М., 2010.

15. Прохорова Н.В. Монеты и банкноты России. - М., 2009. - С. 64.

16. Рикардо Д. Начала политической экономии и налогового обложения. Избранное / Пер. с англ. - М., 2007. Серия «Антология экономической мысли». - С. 720.

17. Русский вес, его развитие и происхождение в связи с историей русских денежных систем с древнейшего времени. 2-е изд. - М., 2011. - С. 69-80.

18. Святловский В.В. Происхождение денег и денежных знаков. 2-е изд. - М., 2010. - С. 12.

19. Сергеевич В.И. Тягло и порядок обложения // Древности русского права: в 3 т. / под ред. и с предисл. А. Томсинова. - М., 2006. Т. 3: Землевладение. Тягло. Порядок обложения. - С. 127.

20. Смит А. Исследование о природе и причинах богатства народов. Серия «Антология экономической мысли» / Пер. с англ. - М., 2007. - С. 102.

21. Финансовая политика Российской империи (XVIII - первая половина XIX вв.): курс лекций. - М., 2008. С. 176-196.

22. Финансовое право: Учебник / А.Р. Батяева, К.С. Бельский, Т.А. Вершило и др. / отв. ред. С.В. Запольский. - М., 2011.- С. 43.

23. Хабибулин А.Г., Селиванов А.И. Стратегическая безопасность российского государства: политико-правовое исследование. - М., 2008. - С. 6.

24. Чертков А. Описание древних русских монет. М., 1834, Кучеров И.И. Историко-правовые аспекты возникновения денег и денежных повинностей // История государства и права. - 2011. - № 17. - С. 23.

25. Энгельс Ф. Происхождение семьи, частной собственности и государства: в связи с исследованиями Льюиса Г. Моргана. 3-е изд. - М., 2010. - С. 27, 122.

\section{References (transliteration):}

1. Bel'skiy K.S. Emissionnoe pravo kak institut finansovogo prava // Gosudarstvo i pravo. - 2006. - № 5. - S. 53.

2. Genezis dokhodov gosudarstva: Monografiya. - M., 2010. - S. 12.

3. Gerbershteyn S. O monete // Moskoviya / Per. A.I. Maleina i A.V. Nazarenko. Kommentariy Z. Nozhnikovoy. Moskva Vladimir, 2008. - S. 192

4. Gorbunova O.N., Gracheva E.Yu. Finansovoe pravo: Uchebnik / Otv. Red. E.Yu. Gracheva, G.P. Tolstopyatenko. - M.: «Prospekt», 2004. - S. 356. 
5. Gur'ev A. Denezhnoe obrashchenie v Rossii v XIX stoletii: Istoricheskiy ocherk. - SPb., 1903. - S. 1-2.

6. Denezhnoe pravo (Finansovo-pravovoe regulirovanie obrashcheniya natsional'noy $\mathrm{i}$ inostrannoy valyuty na territorii RF): Kollektivnaya monografiya. - M.: Elit, 2011. - $272 \mathrm{~s}$.

7. Zapol'skiy S.V. Globalizatsiya ekonomiki: finansovo-pravovoy aspekt // Finansovoe pravo. - 2011. — № 11. - S. 2-6.

8. Kucherov I.I. Istoriko-pravovye aspekty vozniknoveniya deneg i denezhnykh povinnostey // Istoriya gosudarstva i prava. - 2011. - № 17. - S. 20-26.

9. Lisitsyn A.Yu. Sistematizatsiya v emissionnom prave // Reformy i pravo. - 2012. - № 4. - S. 10.

10. Mel'nikova A.S., Dyadchenko O.S. Monetnye klady (svodka kladov i svedeniy o nakhodkakh). - M., 1994. - S. 5.

11. Petukhova N.E. Istoriya nalogooblozheniya v Rossii IX-XX vv.: Uchebnoe posobie. - M., 2008. - S. 11.

12. Pokrovskiy S.P. O den'gakh // Moskovskie universitetskie izvestiya. - 1869. - № 8. - S. 551; Kucherov I.I. Istoriko-pravovye aspekty vozniknoveniya deneg i denezhnykh povinnostey // Istoriya gosudarstva i prava. - 2011. № $17 .-$ S. 24.

13. Popyrin V.I. Ocherki istorii deneg v Rossii. - M., 1948. - S. 12-13; Kucherov I.I. Istoriko-pravovye aspekty vozniknoveniya deneg i denezhnykh povinnostey // Istoriya gosudarstva i prava. - 2011. — № 17. - S. 25.

14. Proiskhozhdenie deneg i denezhnykh znakov. 2-e izd. - M., 2010.

15. Prokhorova N.V. Monety i banknoty Rossii. - M., 2009. - S. 64.

16. Rikardo D. Nachala politicheskoy ekonomii i nalogovogo oblozheniya. Izbrannoe / Per. s angl. - M., 2007. Seriya "Antologiya ekonomicheskoy mysli». - S. 720.

17. Russkiy ves, ego razvitie i proiskhozhdenie $v$ svyazi s istoriey russkikh denezhnykh sistem s drevneyshego vremeni. 2-e izd. - M., 2011. - S. 69-80.

18. Svyatlovskiy V.V. Proiskhozhdenie deneg i denezhnykh znakov. 2-e izd. - M., 2010. - S. 12.

19. Sergeevich V.I. Tyaglo i poryadok oblozheniya // Drevnosti russkogo prava: V $3 \mathrm{t}$. Pod red. i s predisl. A. Tomsinova. M., 2006. T. 3: Zemlevladenie. Tyaglo. Poryadok oblozheniya. - S. 127.

20. Smit A. Issledovanie o prirode i prichinakh bogatstva narodov. Seriya «Antologiya ekonomicheskoy mysli» / Per. $s$ angl. - M., 2007. - S. 102.

21. Finansovaya politika Rossiyskoy imperii (XVIII - pervaya polovina XIX vv.): kurs lektsiy. - M., 2008. - S. 176-196.

22. Finansovoe pravo: Uchebnik / A.R. Batyaeva, K.S. Bel'skiy, T.A. Vershilo i dr.; otv. red. S.V. Zapol'skiy. - M., 2011. - S. 43.

23. Khabibulin A.G., Selivanov A.I. Strategicheskaya bezopasnost' rossiyskogo gosudarstva: politiko-pravovoe issledovanie. - M., 2008. - S. 6.

24. Chertkov A. Opisanie drevnikh russkikh monet. M., 1834, Kucherov I.I. Istoriko-pravovye aspekty vozniknoveniya deneg i denezhnykh povinnostey // Istoriya gosudarstva i prava. - 2011. - № 17. - S. 23.

25. Engel's F. Proiskhozhdenie sem'i, chastnoy sobstvennosti i gosudarstva: v svyazi s issledovaniyami L'yuisa G. Morgana. 3-e izd. - M., 2010. - S. 27, 122. 